of
UNIVERSITY OF MURCIA

\title{
New and Further Approaches to ESP Discourse: Genre Study in Focus
}

\author{
CAMino ReA Rizzo \& Ma ÁNGELES ORTS LLOPIS \\ Universidad de Murcia
}

Amongst all the tools offered by current Linguistics, genre analysis has been virtually adopted by the whole of the collectivity of professionals in English for Specific Purposes studies as the methodological framework of their research activity. Hence, genre theory is solidly established today as a tool for the research into all aspects of professional communication and language variations in different workplace contexts. The concept of genre springs from the theoretical contributions chiefly made by Linguistics above sentence level along with Pragmatics, and derives from the role of English as a lingua franca at the professional and academic world, together with a new interdisciplinary and communicative vision of language (Alcaraz, 2000). Both -the acknowledgement of the essential role of language in the updating processes of the different areas of knowledge, together with that new linguistic perspectivehave generated the special attention given to the theoretical and applied aspects of the academic and professional varieties of English.

As Bhatia and Gotti point out (2006), at their onset, genre studies were basically exploited for the design of language learning and teaching programmes (Bhatia, 1982, 1993; Swales, 1981, 1990; Trimble, 1985), and were restricted to a limited array of specialised genres in the domain of scientific, technological, business, legal and research contexts. However, in more recent years genre studies have started to emphasize not only ESP training in the context of specialised communities, but also the communicative role of texts within textual and social contexts, underlining the social nature of their production and reading. Consequently, since genres are social constructions, communicative devices that operate within a specialized community, genre theory is today being deployed comprehensively, not only to disentangle the complexities beneath communication in different contextual typologies, but also with a view to gain meaning into the intercultural aspects of specialised 
communication, to explore the role of specialised terminology within translation processes in professional contexts, and to go beyond conventional typologies of written and spoken texts towards unconventional approaches that include visual modes and the internet, among others. These studies open to a profitable mutual enrichment in both theoretical and empirical perspectives, and, in fact, an interdisciplinary framework for these branches seems to be even a necessity for their further development.

The underlying objective of the issue is an encouragement for the specialists in these fields to consider how these studies will evolve in the future. The purpose of our volume is, hence, multidimensional and multidisciplinary, mapping the purposes of LSP research to the following:

a. To describe the inner aspects of specialized discourse and the general linguistic competence that underlies ESP training, regardless of the field of study, but taking into account the extra-linguistic cognitive components with which it interacts.

b. To accomplish, beyond the study of sentence-level linguistic features, the study of broad notional forms of discourse in terms of genres with identifiable rhetorical purpose and describable variables to be applied in to the particular professional field.

c. To enquire into language teaching priorities and, accordingly, to offer more adequate input to students' specific competencies and needs within the area of ESP training.

d. To develop contrastive analyses of corpora to explain language variation across languages and genres to explain how professionals communicate within their specialized communicative activities.

e. To encompass the multifaceted dimension of cross-lingual communication in relation to LSP teaching.

The different genres analysed in the present volume may be classified into four different groups of articles, reflecting variegated concerns in the exploration, construction and use of genres in professional, academic and institutional contexts, namely: workplace genres, as those depicting issues to do with everyday communications in the professional sphere; economic and legal genres, having to do with rhetorical structures and lexicon within the fields of law and economics; media genres, in the scope of TV and the written press, and, finally, academic and scientific genres, as those reflecting the discursive practices within the realm of University teaching and research.

The first group deals with specialised genres in workplace contexts, more specifically in context of specialised reports within the realm of medical discourse, in business electronic correspondence and in maritime radiotelephony communication. Carol Berkenkotter studies the possible contradictions between two genres: the institutional genre, in the form of medical certificates - powerful performative speech acts- and a second kind of genre: an oral narrative of personal experience, or ordinary discourse in the form of personal narratives, with very little illocutionary force in comparison. The author's study tells the story of Walter Marshall, a patient of unsound mind who was admitted at a lunatic asylum in Surrey, and 
whose medical certificates and his own oral testimony to the Parliament's Select Committee on Lunacy Laws she uses to integrate concepts from genre analysis and speech act theory in the study of two genres in professional and medical settings. Combining generic and speechact tools, the author tries to unveil how medical certificates had a powerful rhetoric and possessed the ability to result in a sane person's confinement. In opposition, the patient's narrative of personal experience of such confinement, who discovered that much of what he said and did was interpreted as evidence of his insanity. In this way, Berkenkotter takes us on a journey through time as she focuses upon the weaknesses in the medico-legal system in the Victorian era.

Rosa Giménez-Moreno discusses the discourse peculiarities of email messages in business contexts, as the professional world is emphasizing the need for adequate etiquette rules in such written modes of communication in order to avoid harming corporate image and liability. She goes beyond conventional usages of register towards the more complex concept of Register Variation, to account for the notion of proportion in email message writing. Register types -flexible or informal, neutral or standard, distant or formal- are determined not by linguistic features, but by their proportion and combination in accordance with the roles performed by the participants of the communicative process in a due specific context. Accordingly, her study shows that email writers in business contexts frequently use RV as a tool to facilitate communication and improve the relationship with their colleagues. During a sustained exchange of email messages, and depending on their personal purposes and intentions, email writers adopt roles which are more similar to those used with acquaintances and friends rather than those used with colleagues. Therefore -she argues - to a certain extent, proficient mastery of electronic business correspondence is reliant on the user's capacity to recognize and implement peculiar register features.

Finally within this group, Ana Bocanegra Valle's interesting work on Maritime English offers an overview of the way in which communicative interactions in English occur between seafarers when transmitting and receiving information via radiotelephony, a necessary area to scrutinize, since many shipping accidents have their origin in misunderstandings through VHF communications. Supplying a useful account of the features and peculiarities of Maritime English as recommended by the International Maritime Organisation (IMO) and contained in maritime communications manuals, as well as tackling the analysis of standardized verbal message patterns in the context of speech communications at sea through a move-step model, she manages to unveil how particular terminology and specific discourse features are deployed to achieve clarity, brevity and concision in seafaring episodes. With this goal in mind, she makes a clear division between special-purpose and routine messages -respectively subdivided into three and eight message types- and their main conventions and features, as put into practice for efficient communication at sea. All in all, Bocanegra's study raises the awareness for the need of study of standardized language in the area of English for marine communications, both aboard ship and at shore-based stations, a 
field of extreme technical complexity and filled with the restrictions posed by data-protection measures.

The second part of the volume analyses genres in legal and economics fields.

In Jan Engberg and Ismael Arina's contribution U.S. patents, contracts, and regulations on technical matters are compared, in terms of their potential vagueness and communicative purposes and sub-purposes so as to see how all-embracing, all-inclusive legal documents can be. Upon the analysis of a one-million-word corpus, the authors aim to establish knowledge of some of the conventionalised rhetorical strategies used in the abovementioned three legal language genres to accomplish indeterminacy of content, as a necessary characteristic for legal texts to fulfil their pragmatic and communicative purposes. Such strategies may in principle be characteristic of only one of the genres (generic strategies) or may be found in all three genres (inter-generic strategies). On the assumption that nonetheless- there exists a common pool of available rhetorical strategies available for all the three genres under study, the authors find out that, indeed, the use of vague category indicators is common to the three genres under study, playing an important role when trying to point at meaningful vagueness. Three basic ways of expressing such vagueness were found by the authors in the 199 most typical keywords of all three corpora, even if they prove that the situation type underlying the individual genre is more significant than the overarching legal character of the genres, when explicit textual vagueness is introduced.

María Ángeles Orts Llopis and Camino Rea Rizzo's study is based upon a corpus of specialised, semi-specialised and divulgative texts from English digital periodicals in the domain of Telecommunications and Finance. Through the execution of Paul Nation's Range software (Nation \& Heatley, 2002) and the application of the quantitative parameters which condition term detection (Chung, 2003), the authors' goal is the analysis of the lexical coverage in English of the two latest world economic crises: the dot-com bubble, and the Credit Crunch. The definition and identification in terms of terminological volume of the samples in the corpora allows the authors to confirm the existence of consistency in lexical uniformity and/or word recurrence in either subcorpus. They accomplish a qualitative analysis along two different lines: Specific and non-specific words with the highest keyness degree in either corpus, which behave in a specific way when analysed in clusters, or collocations, along the text, on the one hand, and shared words, specific and not specific, with different degrees of keyness in either corpus. This keyness is used to establish that both corpora share similar and dissimilar contents, accounting for the powerful relationship between them and the crises they are expression of.

The third part of the volume includes media genres, in the scope of the written press and TV. Michael White studies how the very prosodic, syntactic and semantic patterns used in constructing headlines as devices to attract the reader's attention also constitute a major hindrance for their comprehension by ESP students. According to the author, headlines are an advantaged kind of genre because of the position and space they command, together with the 
bold print and size they are allotted. Besides those traits, they also boast an idiomatic character, in contrast to more conventional sentence structures, and deliberately deploy sound enhancing devices such as alliteration, rhyme or rhythm for the sake of communication and memorability. If those features constitute clear advantages for the native reader to get a boon from headlines, the non-native English learner may be faced, on the other hand, by the complexity of meaning that such communicative resources evoke. White argues, nonetheless, that the very idiomaticity and phonic and syntactic patterns of headlines may provide insightful clues for the non-native student to understand how the language structure works at large, provided that the right tools are supplied to crack the code. These, he affirms, consist, among other things, of paying attention to phrasal structures rather than single words, and acquiring an awareness of the cohesion and coherence effects these devices set up through metaphor usage. With these, and undertaking a comparison of the complexities of these devices to those of one's mother tongue, the student will gain a new perspective of headlines as highly communicative assets.

The chapter by Stuart Webb analyses television episodes from the premise that television is a useful resource for second-language education, since learning the spoken form of words is useful complement to learning through reading. With the aim to prove how television may indeed be effectively used in L2 training, 288 episodes belonging to three subgenres of the American drama genre are under analysis: medical, spy/action, and criminal forensic investigation, these being compared with different sets of random episodes: The author's results indicate that television programs within the same subgenre are likely to have fewer word families than random television programs, which have much higher lexical coverage. Also, word families are more likely to reoccur in programs from within the same subgenre than in random television programs. Even if the vocabulary size necessary to understand programs may vary between programs and genres, Webb's results show that there may be a trade-off between comprehension and vocabulary learning, since there is likely to be greater understanding of the information in familiar contexts, and these can be used as an incentive to learn unknown items. Hence, when there are difficulties of comprehension and in order to reduce lexical burden, it may be more effective and motivational to watch television programs with related content and storylines than programs with unrelated content.

The last part of the volume deals with academic and scientific genres, as reflections of the discursive practices within the realm of University teaching and research. In the first paper of this section, María Ángeles Alcaraz-Ariza discusses the identification and rhetorical analysis of evaluative speech acts in the context of written medical book reviews from a corpus of 30 samples within The British Medical Journal in the period 2000-2009. If book reviews constitute an important rhetorical means within the academic community to establish authorship identity and group affinity, they also basically involve the assessment of a colleague's work and, therefore, constitute a highly face-threatening act. Potential interpersonal conflict is, thus, usually reduced with the help of varied linguistic and rhetorical 
devices whose analysis Ariza tackles with gusto, as she shows the solid connection between evaluation and pragmatic meaning already acknowledged in other studies. Her scrutiny of acts of evaluation is firmly established as she considers those devices like hedging, singular and plural self-reference pronouns adjectives and adverbs with private prefixes, praise-criticism pairs and modal verbs, deployed to reduce the face-threatening effect of negative evaluation. All in all, she concludes, positive/negative remarks are those whose semantic content openly leads to their positive/negative interpretation, as well as those which can be interpreted as positive or negative depending on the context in which they materialize, no matter if they seem to have a descriptive or ambiguous meaning at first sight.

Last but not least, Gillian Lazar and Eddie Ellis tackle writing assignments used for assessment purposes which arise from a complex interaction of institutional and pedagogic factors. A collaborative programme of teaching and writing support between writing specialists and subject academics is, they claim, an effective way of addressing some of these issues. The active participation of members of both these disciplinary communities in lectures or other teaching sessions, provide students with the opportunity to pinpoint essential characteristics of the corresponding genre, as well as to estimate how these might be creatively conformed to the requirements of a particular domain or the particular perspective of the writer. The authors take academic genre theory as a central issue and examine through it a practical experience in which such theory was applied for certain specific needs. The results of the experiment carried out lead to draw innovative conclusions leaving an open door to further research on academic genre theory and its pedagogical applications, hinting the adequacy of corpus based analyses on this kind of 'hybrid' genres.

The wide range of methodological tools deployed, as well as the variegated areas covered in this volume are proof of the multidimensional character of studies and of the hectic activity displayed in the area of LSP and genre theory today. We are in no doubt about the fact that experts in the area of specialised languages will be much benefited from the way in which generic traits in professional and occupational contexts have been constructed, used, exploited and interpreted in the various chapters of the present IJES issue.

\section{REFERENCES}

Alcaraz Varó, E. (2000). El inglés profesional y académico. Madrid: Alianza Editorial Bhatia, V.K. (1982). An Investigation into Formal and Functional Characteristics of Qualifications in Legislative Writing and its Application to English for Academic Legal Purposes. Ph.D thesis. University of Aston in Birmingham.

Bhatia, V. K. (1993). Analysing Genre: Language Use in Professional Settings. London: Longman. Bhatia, V.K. \& Gotti M.(eds) (2006) Explorations in Specialised Genres. Bern: Peter Lang.

Chung, T. (2003). A corpus comparison approach for terminology extraction. Terminology, 9(2), 221246.

Nation, I. S. P., \& Heatley, A. (2002). Range: A program for the analysis of vocabulary in texts [software]. Retrieved from http://www.victoria.ac.nz/lals/staff/paul-nation/nation.aspx 
Swales, J.M. (1981). Aspects of Article Introductions. Aston ESP Research Report No 1. Language Studies Unit, University of Aston in Birmingham, UK.

Swales, J.M. (1990). Genre Analysis. Cambridge: Cambridge Textbooks in Linguistics.

Trimble, L. (1985). English for Science and Technology: A Discourse Approach. Cambridge: Cambridge University Press. 